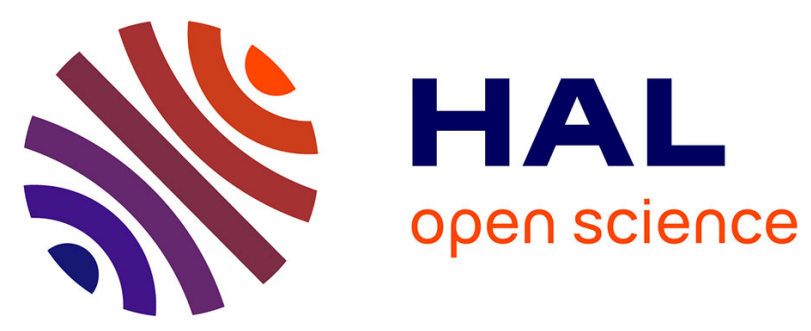

\title{
Influence of multiwall carbon nanotube (MWCNT) dispersion on ignition of poly (dimethylsiloxane)-MWCNT composites
}

\author{
Rodolphe Sonnier, Liliane Bokobza, Nicolas Concha Lozano
}

\section{To cite this version:}

Rodolphe Sonnier, Liliane Bokobza, Nicolas Concha Lozano. Influence of multiwall carbon nanotube (MWCNT) dispersion on ignition of poly (dimethylsiloxane)-MWCNT composites. Polymers for Advanced Technologies, 2015, 26 (3), pp.277-286. 10.1002/pat.3454 . hal-02914237

\section{HAL Id: hal-02914237 \\ https://hal.science/hal-02914237}

Submitted on 4 Jun 2021

HAL is a multi-disciplinary open access archive for the deposit and dissemination of scientific research documents, whether they are published or not. The documents may come from teaching and research institutions in France or abroad, or from public or private research centers.
L'archive ouverte pluridisciplinaire HAL, est destinée au dépôt et à la diffusion de documents scientifiques de niveau recherche, publiés ou non, émanant des établissements d'enseignement et de recherche français ou étrangers, des laboratoires publics ou privés. 


\title{
Influence of multiwall carbon nanotube (MWCNT) dispersion on ignition of poly (dimethylsiloxane)-MWCNT composites
}

\author{
Rodolphe Sonnier*, Liliane Bokobza and Nicolas Concha-Lozano
}

\begin{abstract}
Poly(dimethylsiloxane) (PDMS) filled with low contents of multiwall carbon nanotubes (MWCNT) was prepared using different ways to monitor the dispersion of MWCNT. The influence of the dispersion on thermal conductivity and transmittance was measured. High degree of transparence can be achieved with 0.02 phr of well dispersed MWCNT. Time-to-ignition (TTI) was also measured on 2- or 4-mm-thick specimens heated using radiative unidirectional source. Time-to-ignition was found to decrease with the incorporation of MWCNT because more heat is absorbed at the surface. Higher time-to-ignition was observed for partially translucent composites, due to different absorption in-depth profiles. It can be assumed that time-to-ignition can be controlled by the dispersion of MWCNT into the polymeric matrix.
\end{abstract}

Keywords: poly(dimethylsiloxane); carbon nanotubes; ignition; optical and thermophysical properties

\section{INTRODUCTION}

Nowadays, nanoparticles have become a class of flame retardants (FR), even if they are not efficient enough to pass some standardized tests, ${ }^{[1,2]}$ and they are often used in combination with more classical FRs (for example phosphorus additives).

It is well-known that nanoparticles, essentially those with a high aspect ratio such as clays or carbon nanotubes, can improve significantly the flame retardancy of polymers on account of the formation of an interconnecting filler network at a low filler loading acting as a protective heat shield. But the reduction in flammability can only be achieved if the particles are well dispersed in the host polymeric medium. ${ }^{[3-5]}$ Most articles dealt with the role of these nanoparticles on the peak of heat release rate (pHRR) which is considered as the main parameter to assess the fire hazard.

Time-to-ignition (TTI) is another key parameter to control. For example, Eurocodes rating depends on the total heat release (THR) after $600 \mathrm{~s}$ (measured using the Single Burning Item test). For this test, if ignition is delayed, THR at $600 \mathrm{~s}$ can be lowered.

In many cases, nanoparticles lead to lower TTI. For example, Kashiwagi et al. observed a decrease in TTI for PMMA and PS containing organomodified clays or single-walled carbon nanotubes (SWCNT) ${ }^{[6]}$ Ignition is governed by several material parameters, namely thermal stability, thermal conductivity, emissivity, absorption in-depth, density and specific heat. Patel et al. have pointed out the influence of these parameters on heat release rate curves using Thermakin software. ${ }^{[7]}$

The effect of SWCNT or MWCNT on time-to-ignition is quite complex. Kashiwagi's team has extensively studied the role of SWCNT or MWCNT on the flammability of various polymers (PMMA, PS and PP). ${ }^{[3,6,8-10]}$ These authors observed that TTI of PP-MWCNT decreases at low MWCNT content (0.5 wt\% or less) but increases at higher content. They explained that MWCNT allows higher heat absorption in the vicinity of the surface leading to a higher heating rate and a faster ignition. But at higher
MWCNT content, thermal conductivity is increased and counterbalances this first effect: heat is more efficiently removed from the surface to the composite bulk, and the surface temperature increases more slowly. ${ }^{[8]}$

Except density and heat capacity which can be estimated according to a linear rule of mixtures, the other properties previously cited depend strongly on the morphology of the composite. Therefore, monitoring these properties can be a suitable approach to control the flammability and particularly the ignition. Recently several papers focused on the thermo-optical or thermo-physical properties to assess or to improve the flame retardancy of various materials and especially their time-toignition. Schartel et al. have shown that a coating acting as an infrared mirror can be a powerful strategy to delay ignition. ${ }^{[1]}$ Flame retardancy of an epoxy resin nanocomposite was assigned to higher reradiation due to high emissivity of the thermally stable barrier layer. ${ }^{[12]}$ High reflectance of SWNT and poly(acrylonitrile-co-methacrylate)-SWNT films was measured by Bellayer et al. ${ }^{[13]}$ This result is somewhat surprising because it should lead to higher time-to-ignition, in contradiction with many results. Indepth radiative heat transmittance was pointed out to explain the heating rate of nanocomposites PP/nanoclay ${ }^{[14]}$ or the shielding effect of silica layer formed during silicone degradation. ${ }^{[15]}$ Modeling the absorption in-depth was attempted by several authors. ${ }^{[16,17]}$ A better thermal barrier of a silicone-based coating was assigned to the lower thermal diffusivity of the residue at high temperature. ${ }^{[18]}$ Even bubbling was considered as an important parameter influencing the flame retardancy of

\footnotetext{
* Correspondence to: Rodolphe Sonnier, Centre des Matériaux de l'Ecole des Mines d'Alès, 6, Avenue de Clavières, 30319 Alès Cedex, France.

E-mail: rodolphe.sonnier@mines-ales.fr

R. Sonnier, L. Bokobza, N. Concha-Lozano

Centre des Matériaux de l'Ecole des Mines d'Alès, 6, Avenue de Clavières, 30319, Alès Cedex, France
} 
poly(ether ether ketone) (PEEK) because it changes the optical properties of the material above its melting temperature. ${ }^{[19]}$

Fina et al. have explained that the higher in-depth absorption of PP-nanoclay composites depends not only on the infrared absorbance of the nanoclays but also on the scattering which is itself controlled by the nanoparticle dispersion. ${ }^{[14]}$ Therefore, the objective of this work is to assess the influence of the dispersion of MWCNT on the time-to-ignition of PDMS composites and to identify the relevant parameters controlling the ignition process. It has to be mentioned that PDMS displays an unexpected affinity for carbon nanotubes as revealed by the huge increase in viscosity upon addition of carbon nanotubes into the unfilled silicone matrix. The increase in viscosity is much more important than that imparted by other types of fillers such as layered or fibrous clays. ${ }^{[20]}$ This unexpected affinity was assumed, through modeling studies, to be connected to strong $\mathrm{CH}-\pi$ interactions between the PDMS methyl groups and the $\pi$-electron-rich surface of the carbon nanotube. A tiny amount of CNTs is required to make an electrically conductive polymer associated with the formation of an interconnecting filler network since the drop in resistivity is observed at a filler loading as low as 0.05 phr ( $p h r=$ parts of filler per hundred parts of rubber). On the other hand, a same reinforcement of the unfilled matrix is achieved at a much lower filler content than highly reinforcing silicas. ${ }^{[21,22]}$

\section{EXPERIMENTAL}

\section{Materials}

Multiwall carbon nanotubes (MWCNTs) were purchased from Nanocyl S.A. (Belgium). In this study, we have used the Nanocyl 7000 series (purity: 90\%) produced via the catalytic carbon vapor deposition process, without any further purification. Their average diameter and length are around $10 \mathrm{~nm}$ and $1.5 \mu \mathrm{m}$, respectively, and their surface area between 250 and $300 \mathrm{~m}^{2} \mathrm{~g}^{-1}$. The average diameter as determined from the TEM micrographs is quite similar to that reported by the supplier.

Hydroxyl-terminated PDMS (average molecular weight of $18,000 \mathrm{~g} \mathrm{~mol}^{-1}$ ) was purchased from Gelest. Tetraethoxysilane (TEOS) and stannous-2-ethyl-hexanoate were supplied by Aldrich

In order to investigate the effect of a surfactant on the dispersion of MWCNTs, Nanosperse AC (NaAC) obtained from NanoLab Inc. was used as an agent for the functionalization of carbon nanotubes. NaAC that is a surfactant for the preparation of polar solvent-based suspensions of carbon nanotubes is a solution containing a terpolymer of polyvinyl butyral, polyvinyl alcohol and polyvinyl acetate, dissolved in THF, with a proprietary additive. $\mathrm{NaAC}$ (NaAC/MWCNTs ratio = 1:1 by weight) was added in the beaker before and also during sonication.

\section{Preparation of the composites}

The unfilled network was prepared from the hydroxyl-terminated PDMS by an endlinking reaction with tetraethoxysilane (TEOS) as the cross-linking agent and stannous-2-ethyl-hexanoate as the catalyst (used in the extent of $1 \mathrm{~g} / 100 \mathrm{~g}$ of PDMS chains). Theoretically, a stoichiometric balance between ethoxy groups of the tetrafunctional alkoxysilane cross-linker and the hydroxyl chain ends of the PDMS precursor chain should lead to model networks in that the molecular weight $M_{c}$ between cross-links is predetermined as well as the functionality of the cross-links (specifically 4). In fact, as already reported in the literature, ${ }^{[23]}$ the end-linking reaction requires larger amounts of TEOS than the stoichiometric equivalent. In this study, an excess of TEOS of $50 \%$ with regard to the stoichiometric conditions was used to ensure correct elastic modulus $(0.13 \mathrm{MPa})$ and reasonable soluble fraction (between 2 and 3\%).

Nanotube dispersion in a host medium is really a challenge on account of the tendency of pristine tubes to assemble into bundles. It has been observed that homogeneous distributions of CNTs in the resulting material can be achieved by sonicating CNTs in a suitable solvent before incorporating the solution in the polymer. For the preparation of the PDMS/MWCNT composite, the adequate amount of MWCNTs was dispersed in isopropyl alcohol (1 mg of MWCNTs in $10 \mathrm{ml}$ of solvent) by sonicating the suspension for 30 min using a Vibra-Cell VCX 500 operating at $40 \%$ amplitude with on and off cycles, respectively, equal to 4 and $2 \mathrm{sec}$. After a rest of $30 \mathrm{~min}$, the mixture was submitted to a further sonication for $30 \mathrm{~min}$. PDMS was then mixed to the MWCNT suspension by agitation under magnetic stirring until total evaporation of the alcohol. The cross-linking agent and then the catalyst were incorporated, and after further mixing for a few minutes, the mixture was slowly cast into a Teflon mold and left overnight at room temperature for complete curing.

Composites were also prepared in the presence of the surfactant (surfactant/MWCNT ratio = 1:1 by weight), added before the sonication procedure and also after dispersion of the nanotubes. In the first case (way 1), the nanotubes and the surfactant were sonicated in isopropyl alcohol as described above, while in the latter case (way 2, only for 2-mm-thick PDMS with $0.02 \mathrm{phr}$ of MWCNT), the nanotubes were first sonicated in isopropyl alcohol, the surfactant is then added and the whole mixture was submitted again to a further sonication for $30 \mathrm{~min}$.

Only low MWCNT contents can be used, not higher than 0.1 phr, on account of the strong increase in viscosity that hinders the cross-linking process. Two and 4-mm-thick composites containing $0,0.02,0.04,0.06,0.08$ and 0.1 phr of MWCNT with and without surfactant were prepared (except the 4-mm-thick composites containing 0.06 and 0.08 phr of MWCNT with surfactant).

\section{Characterization}

Time-to-ignition (TTI) of composites was measured using "epiradiator test" (french standard NFP 92-505) equipped with an infrared pyrometer. In this test, $50 \times 50 \times 4$ (or 2) $\mathrm{mm}^{3}$ specimens are exposed to a $500-\mathrm{W}$ radiator (diameter $10 \mathrm{~cm}$, made of opaque quartz). Specimens are placed on a grid located $30 \mathrm{~mm}$ under the bottom of the epiradiator. The heat flux on the surface of the specimen was measured equal to $37 \mathrm{~kW} / \mathrm{m}^{2}$. An infrared pyrometer (Optris CT) is placed perpendicularly to the surface below the specimen in order to measure the temperature of the lower surface through the grid hole (the hole size is approximately $2 \times 2 \mathrm{~cm}^{2}$ ). Infrared (IR) pyrometer measures wavelengths in the range of 8-14 $\mu \mathrm{m}$. A scheme of the apparatus is shown in Fig. 1. Two or three specimens were tested for each composite. In all cases, both tests lead to consistent results (difference in TTI was less than $3 \mathrm{~s}$, except for one composite- $-5 \mathrm{~s}$ ).

Additional experiments were carried out using epiradiator equipped with IR camera (Optris) in order to evaluate the respective influence of emissivity and absorption in-depth. One sample is cut into two equal parts which are positioned one beside the other on the grid. One part is coated with graphite on both surfaces (Fig. 2). The second one is coated with graphite only on the 


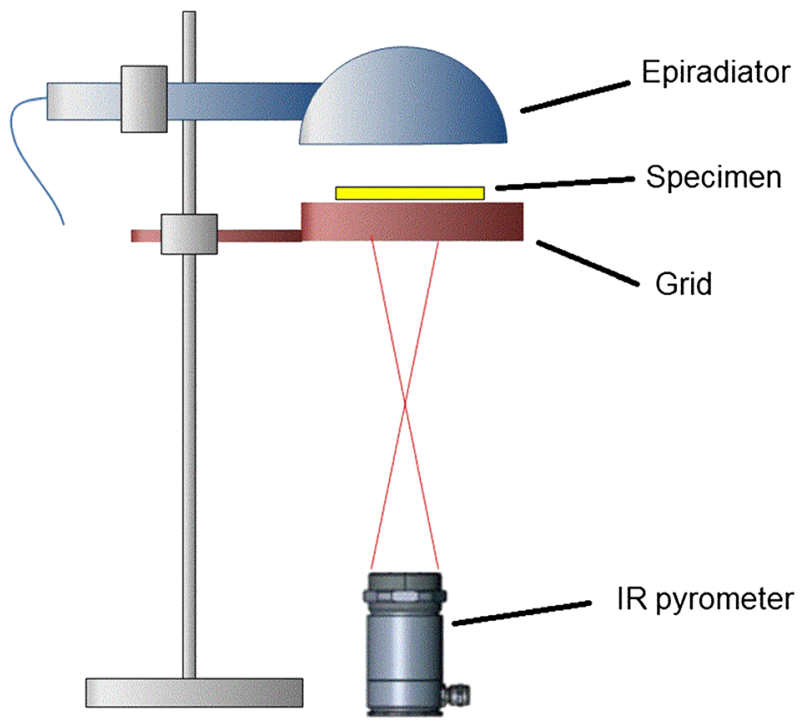

Figure 1. Scheme of epiradiator test equipped with IR pyrometer. This figure is available in colour online at wileyonlinelibrary.com/journal/pat

lower surface. The distance between the grid and the epiradiator was fixed at $45 \mathrm{~mm}$, and the power of the epiradiator was decreased to limit the heat flux and to allow a more progressive heating of the specimen. The emissivity of the lower surfaces of both parts is equal to 1 , and therefore the temperature measured by the IR camera is correct. Moreover, heat flux is not directly transmitted, and it is absorbed by the graphite coating (on upper or lower surfaces).
Thermal stability was evaluated using a Perkin-Elmer thermogravimetric analyzer. Ten to twelve milligrams of a sample was heated up to $700^{\circ} \mathrm{C}$ at $10^{\circ} \mathrm{C} / \mathrm{min}$ under air flow.

The transmittance was measured in the infrared spectral range in order to focus on thermal radiation heat transfer properties. In this study, the transmittance is defined as the total amount of light absorbed and scattered through the thickness of the polymer slab. The measurements were performed using a simple device composed of an infrared emitter and a phototransistor with wavelength peak sensitivity at $940 \mathrm{~nm}$ (Fig. 3). The electrical circuit and the optoelectronic components of the device were used in their linear response range with the incident radiative flux.

First, the measurement of the incident radiative flux $\left(\mathrm{l}_{0}\right)$ is performed without sample. Second, the transmitted radiative flux $\left(I_{1}\right)$ was measured through the sample. The transmittance of the sample $T$ was calculated according to eqn (1)

$$
\mathrm{T}=\mathrm{I}_{1} / \mathrm{I}_{0}
$$

The thermal diffusivity $D\left(\mathrm{~m}^{2} / \mathrm{s}\right)$ of the composites was measured using a Laser Flash apparatus (XFA600 from Linseis). The specimens were stamped from $100 \times 100 \times 2 \mathrm{~mm}^{3}$ sheets and coated with graphite on both surfaces. Measurements were carried at ambient temperature in vacuum. Values were averaged over five measurements. The thermal conductivity $\lambda\left(\mathrm{W} / \mathrm{m}^{\circ} \mathrm{C}\right)$ is calculated from thermal diffusivity, specific heat $\mathrm{c}\left(\mathrm{J} / \mathrm{kg}^{\circ} \mathrm{C}\right)$ and density $\rho\left(\mathrm{kg} / \mathrm{m}^{3}\right)$ according to eqn (2)

$$
\lambda=\mathrm{D} \times \rho \times \mathrm{C}
$$
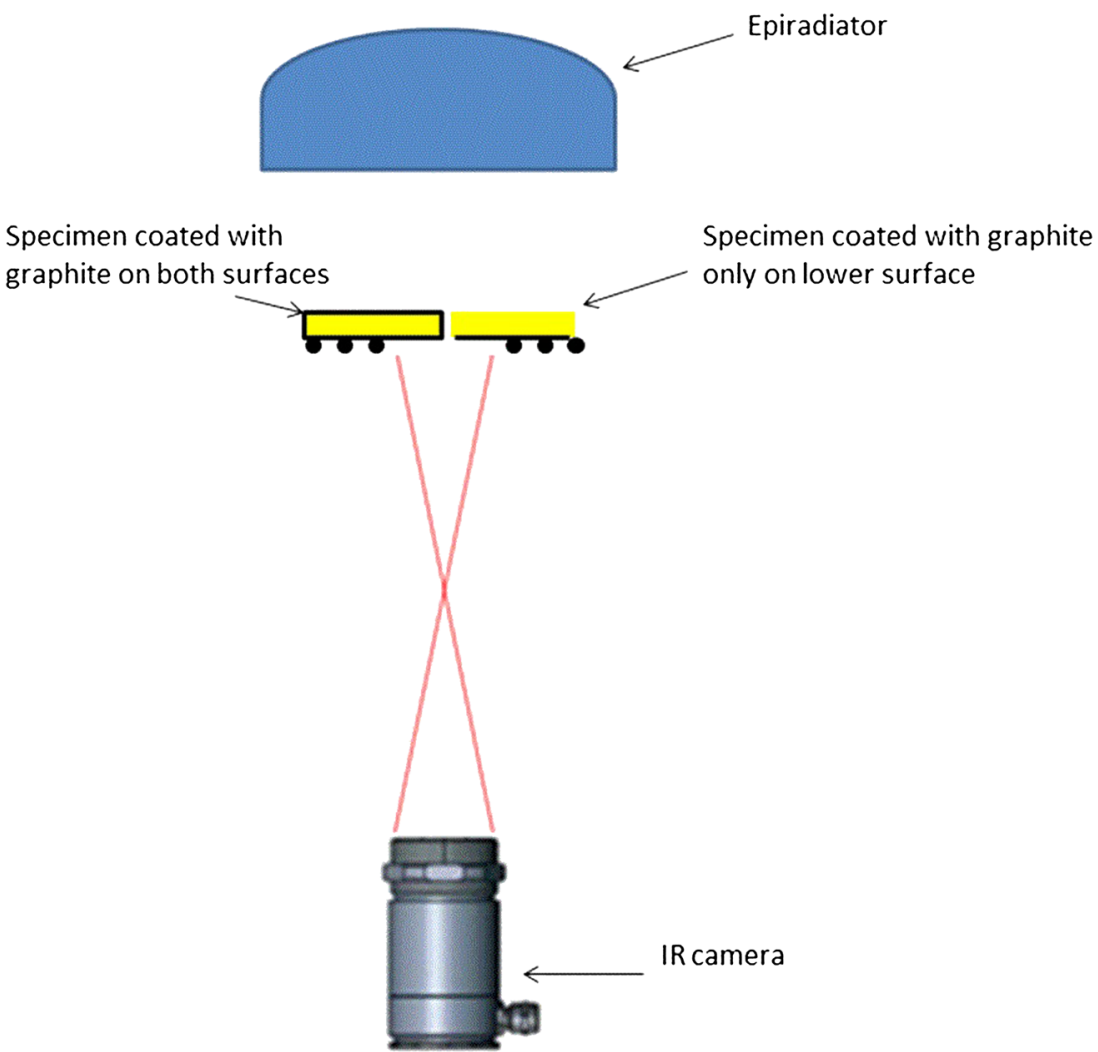

Figure 2. Scheme of epiradiator test equipped with IR camera. This figure is available in colour online at wileyonlinelibrary.com/journal/pat 


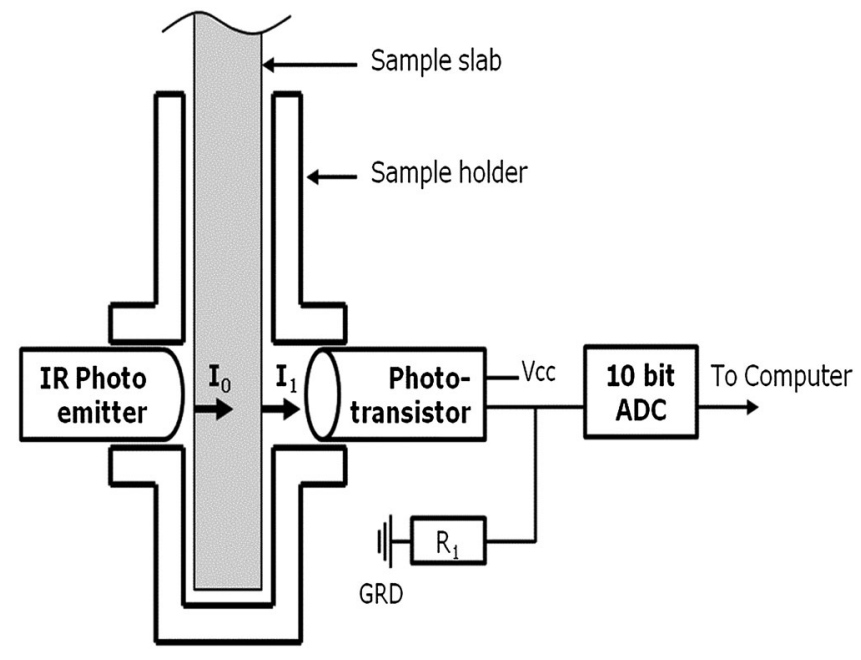

Figure 3. Diagram of the device used to measure the transmittance of a polymer slab in the infrared spectral range. The transmittance is defined as the ratio of incident $\left(\mathrm{I}_{0}\right)$ and transmitted radiative flux $\left(\mathrm{I}_{1}\right)$.

Specific heat $c$ and density $\rho$ were measured only for pure PDMS: respectively, $1.6 \mathrm{~J} / \mathrm{g} .{ }^{\circ} \mathrm{C}$ and $980 \mathrm{~kg} / \mathrm{m}^{3}$ at ambient temperature. Specific heat was measured using a Perkin Elmer differential scanning calorimetry (Stepscan software). Density was measured using a helium Pycnometer (Micromeritics AccuPyc 1330). Considering the very low content of MWCNT (0.1 phr or less), these values are assumed to be similar for all composites.

\section{RESULTS AND DISCUSSION}

The macroscopic aspect of composites changes significantly according to the method of preparation and essentially to the presence of the surfactant. When no surfactant is used, composites are fully opaque, even at lowest thickness $(2 \mathrm{~mm})$ and MWCNT content (0.02 phr). On the contrary, as expected, translucent composites can be obtained when the synthesis is carried out by using a surfactant (see Fig. 4), evidencing that dispersion is clearly improved.

The use of a surfactant acting as a non-covalent treatment has been shown to be an effective way to ensure homogeneous and stable dispersion throughout the solvent and in the composite host material. Vaisman et al. have suggested a mechanism involving the formation of spaces or gaps at the bundle ends by the high local shear provided by ultrasonication and the propagation of the debundling by surfactant adsorption separating the individual nanotubes from the bundle. ${ }^{[24]}$ But Dyke and Tour explain that exfoliation of the bundles must occur previous to surface treatment in order to obtain individual tubes because the outermost nanotubes in a bundle are probably more treated than the innermost tubes. ${ }^{[25]}$ In that case, the nanotubes are expected to remain predominantly bundled after the surfactant treatment. In other words, the surfactant bounds itself to the undispersed nanotubes and holds them together. The presence of bundled structures tied by the surfactant has been effectively observed in PS/MWCNT composites when the surfactant is added before the previous dispersion of the nanotubes by ultrasonication. ${ }^{[26]}$ The surfactant is expected to work by wrapping around the dispersed nanotubes and preventing them from reagglomerating.

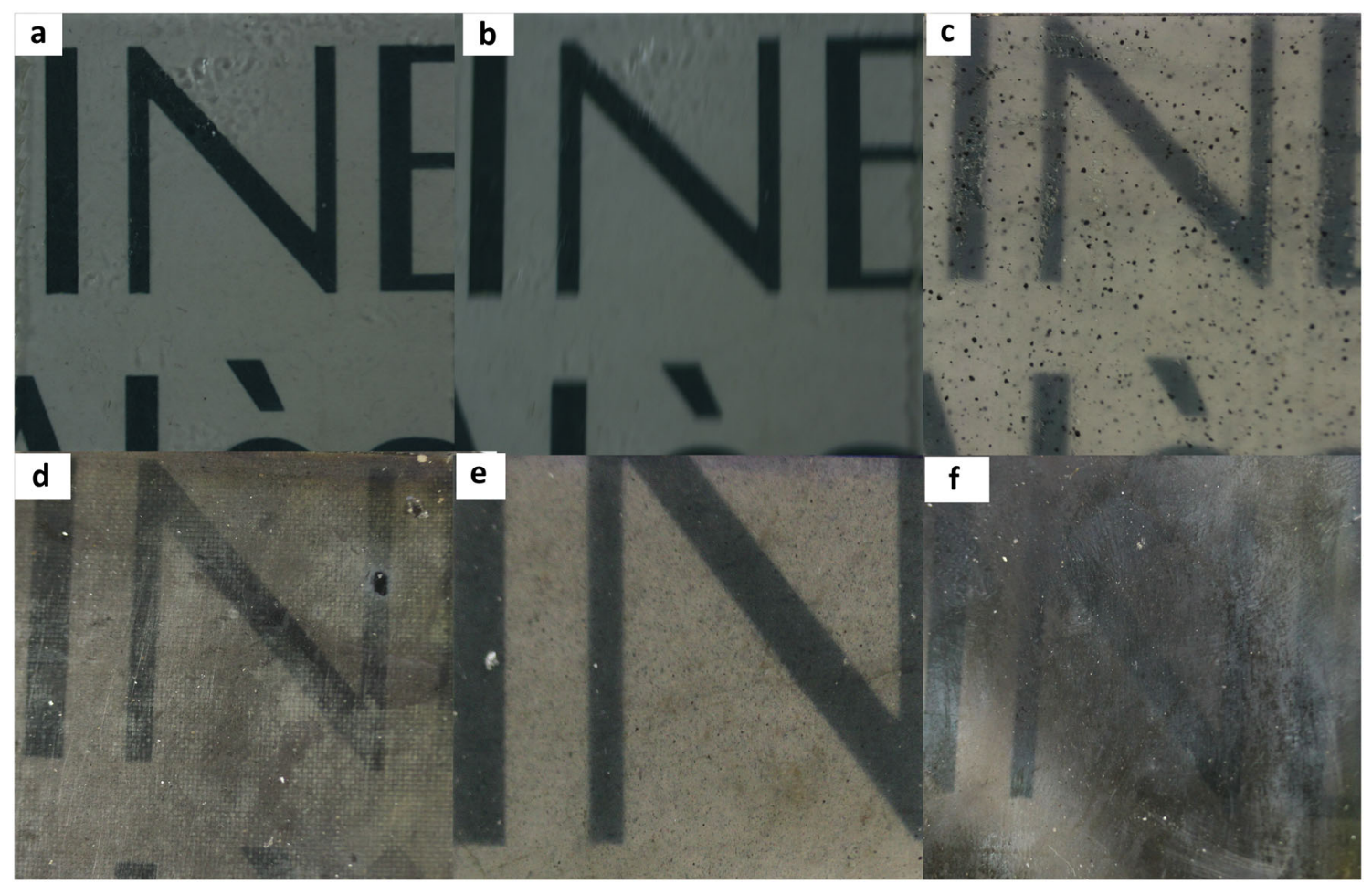

Figure 4. Pictures of various composites; a-PDMS $2 \mathrm{~mm}$ (0.9), b-PDMS $4 \mathrm{~mm}$ (0.88), c-PDMS with 0.02 phr MWCNT with surfactant $4 \mathrm{~mm}(0.48)$, $\mathrm{d}$ -PDMS with 0.02 phr MWCNT with surfactant $2 \mathrm{~mm}$ (way 2-0.23), e-PDMS with 0.02 phr MWCNT with surfactant 2 mm (way 1-0.41) and f-PDMS with 0.04 phr MWCNT with surfactant $2 \mathrm{~mm}$ (0.11); transmittance values are given into brackets; all other composites are fully opaque; the size of the $\mathrm{N}$ letter is approximately $2 \times 2.5 \mathrm{~cm}^{2}$. This figure is available in colour online at wileyonlinelibrary.com/journal/pat 
To quantify the observed differences between the different composites, transmittance was evaluated (Fig. 5). Above 0.04 phr of MWCNT, transmittance is close to 0 , whichever the method used to disperse the nanotubes. But higher transmittance values (as far as 0.48) can be achieved at $0.04 \mathrm{phr}$ and especially $0.02 \mathrm{phr}$ of MWCNT even for thick specimen $(4 \mathrm{~mm})$. Such a difference in transmittance of composites is assigned to the dispersion level of MWCNT. It also appears that the way of preparing the composites affects the transmittance of the sample (please also compare Fig. $4 \mathrm{~d}$ and e).

It could be surprising that some thick composites are partially translucent. In fact, in most studies, the MWCNT content is much higher than in our work. Shahzad et al. have prepared thin films of PDMS containing 0.5 to 3 wt $\%$ of well-dispersed MWCNT. ${ }^{[27]}$ According to the absorption coefficient $\mu\left(\mathrm{m}^{-1}\right)$ calculated by the authors (close to $5000 \mathrm{~m}^{-1}$ ) for PDMS with $0.5 \mathrm{wt} \%$ of MWCNT, the transmittance is assumed to be negligible for 2mm-thick samples. Only very low contents of MWCNT allow achieving translucent composites. To obtain a transmittance equal to 0.5 for a 2 -mm-thick composite, the absorption coefficient must be close to $150 \mathrm{~m}^{-1}$. Considering that absorption coefficient is roughly proportional to MWCNT content and assuming that its value is almost null for pure PDMS, such low absorption coefficient corresponds to a MWCNT content of $0.015 \mathrm{wt} \%$ in good agreement with our findings.

Time-to-ignition was measured using epiradiator test (Fig. 6). TTI was found close to $45 \mathrm{~s}$ for pure PDMS with a thickness of $4 \mathrm{~mm}$. TII decreases up to $29 \mathrm{~s}(-16 \mathrm{~s})$ for PDMS filled with 0.1 phr of MWCNT directly incorporated (without surfactant). The decrease in $\mathrm{TI}$ is observed for composites containing low content of MWCNT (0.02 and 0.04 phr). Above 0.04-0.06 phr, TTI does not change anymore.

For thin specimens (2-mm thickness), $\mathrm{TT}$ is obviously reduced (42 s for pure PDMS, $27 \mathrm{~s}$ for PDMS filled with $0.08 \mathrm{phr}$ of MWCNT), but the tendency is similar: $\mathrm{TI}$ decreases when MWCNT content increases up to $0.04 \mathrm{phr}$ and then becomes constant.

Figure 6 also points out that the method of preparation is very influent on TTl, especially for composites containing $0.02 \mathrm{phr}$ of MWCNT. Using surfactant allows increasing Tा। of thick specimens from $34-36 s$ to $44-46 s$ (+10s), i.e. as high as for pure
PDMS. Similarly for thin specimens, $\mathrm{TI}$ increases from $32 \mathrm{~s}$ to 37-40 s.

Therefore it can be assumed that the dispersion of MWCNT (controlled by the method of preparation) has a great influence on the ignition of PDMS.

In the following, we discuss the influence of various material parameters (controlled by the presence of MWCNT) on time-toignition. Modeling time-to-ignition of squared sheets of polymers exposed to a constant heat flux has already been performed by Quintière et al. ${ }^{[28,29]}$

For thermally thick specimens, the reciprocal of the square root of TII changes linearly with heat flux qext" and depends mainly on various optical and thermophysical properties (emissivity $\varepsilon$, thermal conductivity $k$, specific heat $\mathrm{c}$ and density $\rho-$ eqn (3). For thermally thin specimens, thermal conductivity is not influent anymore, and thickness must be taken into account. ${ }^{[30]}$ Equation to model TTI for thick specimens is:

$T T I^{-1 / 2}=\left(\frac{\varepsilon}{\sqrt{\frac{2}{3} k \rho c}\left(T_{i g}-T_{0}\right)}\right) q_{\text {ext }}^{\prime \prime}-\left[\frac{h_{c}\left(T_{i g}-T_{0}+\varepsilon \sigma T_{i g}{ }^{4}\right)}{\sqrt{\frac{2}{3} k \rho c}\left(T_{i g}-T_{0}\right)}\right]$

Where $T_{0}$ and $T_{i g}$ are room temperature and temperature of ignition, respectively, $h_{c}$ is a convective heat transfer coefficient and $\sigma$ is the Stefan-Boltzmann constant.

It must be noticed that this equation considers that heat can be reflected (if emissivity is lower than 1). But heat is believed to be absorbed fully at the sample surface. Absorption in-depth is not taken into account. Other more complex models were proposed to take into account absorption in-depth. ${ }^{[16]}$ Another limit of this model (and other ones) is that material properties continuously change when the temperature increases up to the temperature of ignition. However, these properties are scarcely measured over the whole range of temperature, and values at room temperature are generally considered.

Among material properties, we have already found that density and specific heat do not explain the changes in time-toignition. Other properties include thermal conductivity, thermal

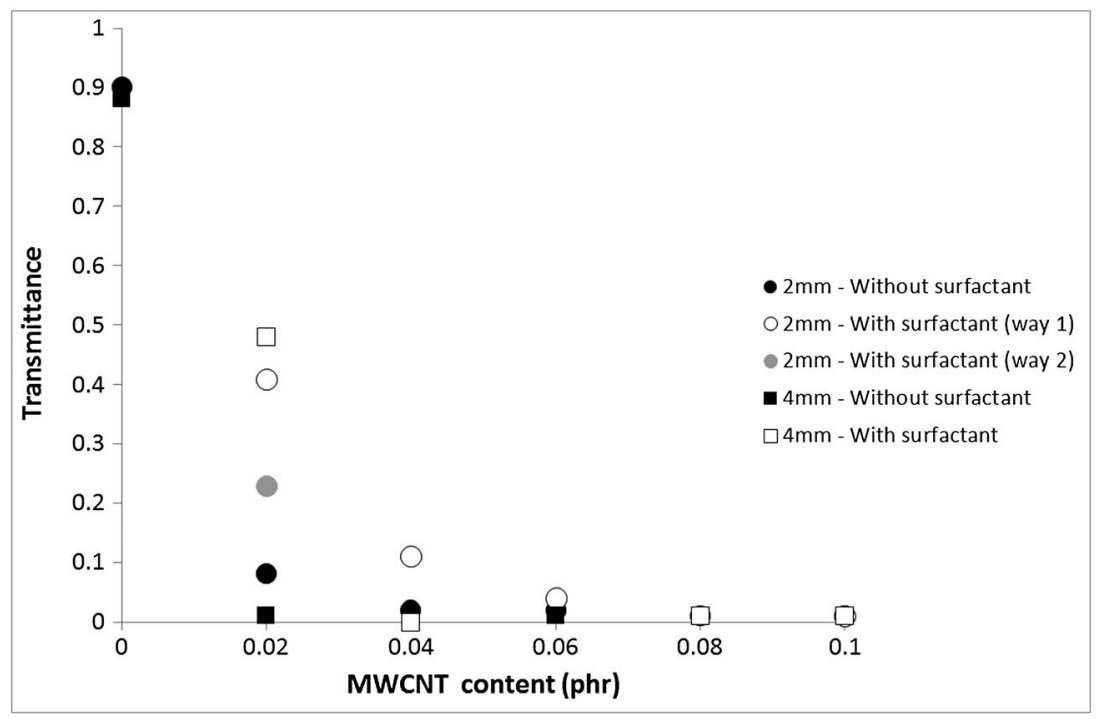

Figure 5. Transmittance versus MWCNT content for composites prepared with and without surfactants. 


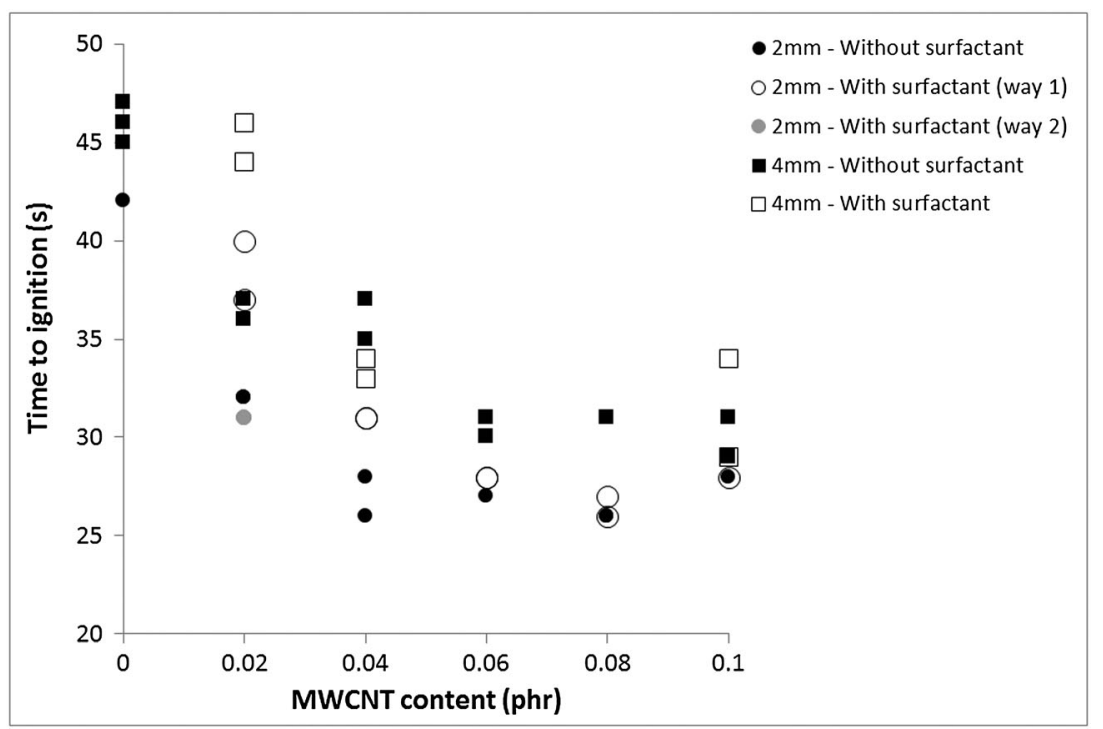

Figure 6. Time-to-ignition versus MWCNT content for composites prepared with and without surfactants.

stability (i.e. temperature of ignition in eqn (3)), emissivity and absorption in-depth.

Thermal diffusivity and thermal conductivity were found between 0.0010 and $0.0015 \mathrm{~cm}^{2} / \mathrm{s}$ and 0.16 and $0.23 \mathrm{~W} / \mathrm{m}{ }^{\circ} \mathrm{C}$, respectively, whichever the content of MWCNT and the method used to prepare the composites. No significant tendency was observed with the incorporation of MWCNT (see Fig. 7). Even if the thermal conductivity is slightly lower than the value reported for pure PDMS $\left(0.25 \mathrm{~W} / \mathrm{m}^{\circ} \mathrm{C}\right.$ according to Han and Fina $\left.{ }^{[31]}\right)$, this result is in good agreement with the literature data. Taking into account the uncertainties (assessed to $0.02 \mathrm{~W} / \mathrm{m}^{\circ} \mathrm{C}$ ), the slightly higher value for the composite containing $0.1 \mathrm{phr}$ of MWCNT without surfactant does not appear significant. In their review, Han and Fina have summarized many studies about the thermal conductivity of various polymers filled with MWCNT. ${ }^{[31]}$ Incorporation of MWCNT leads to a very moderate increase in thermal conductivity, far below the values calculated according to a rule of mixture (parallel model), even with MWCNT contents much higher than those used in the present study. The authors explain these disappointing results by two phenomena: interfacial resistance (between polymer and MWCNT) and contact resistance (between two nanotubes). Hong et al. have incorporated MWCNT in PDMS according to two ways (direct incorporation or use of a masterbatch). ${ }^{[32]}$ Thermal conductivity increased from 0.234 to $0.287 \mathrm{~W} / \mathrm{m}^{\circ} \mathrm{C}$ with a direct incorporation of $2 \mathrm{phr}$ of MWCNT. When masterbatch was used, thermal conductivity was slightly higher $\left(0.315 \mathrm{~W} / \mathrm{m}^{\circ} \mathrm{C}\right)$. While the maximum content of MWCNT is 0.1 phr in our study, it is not surprising that thermal conductivity remains constant for all composites. A recent study on styrene-butadiene rubber with containing MWCNT content up to $10 \mathrm{phr}$ showed that the increase in thermal conductivity of the composites remains modest with regard to that of isolated MWCNT and that measured for mats or bundles. ${ }^{[33]}$ The presence of gaps in the carbon nanotube network and scattering defects is known to reduce the efficiency of heat transfer.

Therefore, changes in time-to-ignition cannot be assigned to modifications of thermal conductivity.

Thermal stability is also a key parameter governing the ignition through the temperature of ignition. Temperature of ignition is dependent on material but relatively independent on

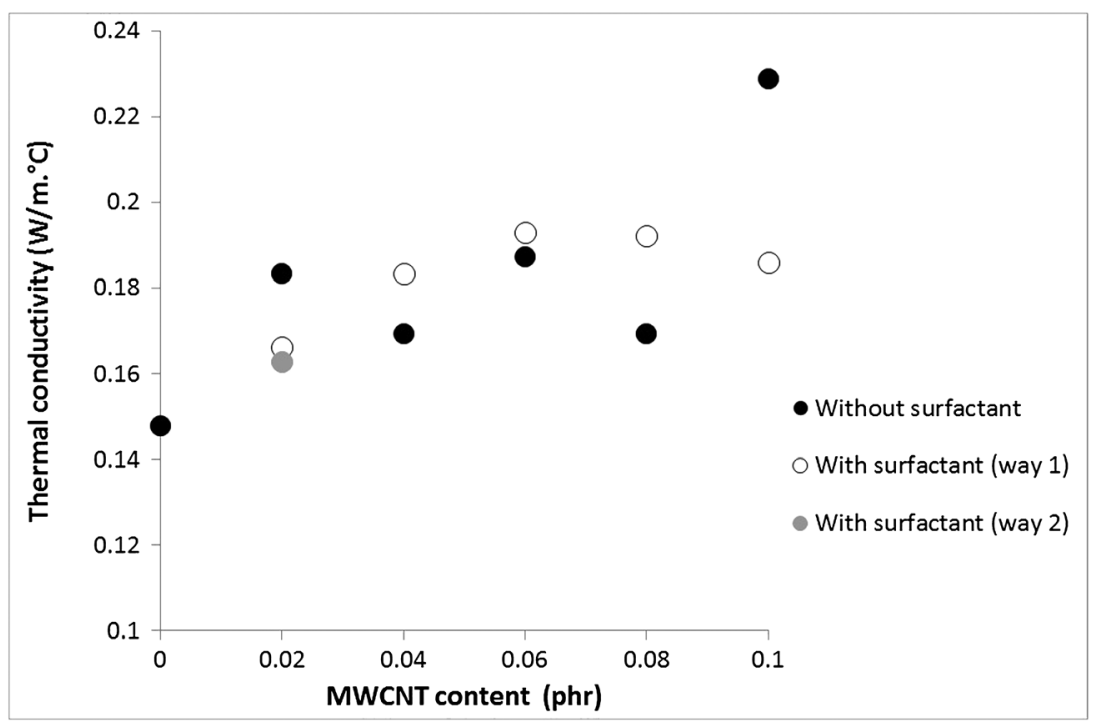

Figure 7. Thermal conductivity versus MWCNT content for composites prepared with and without surfactants. 


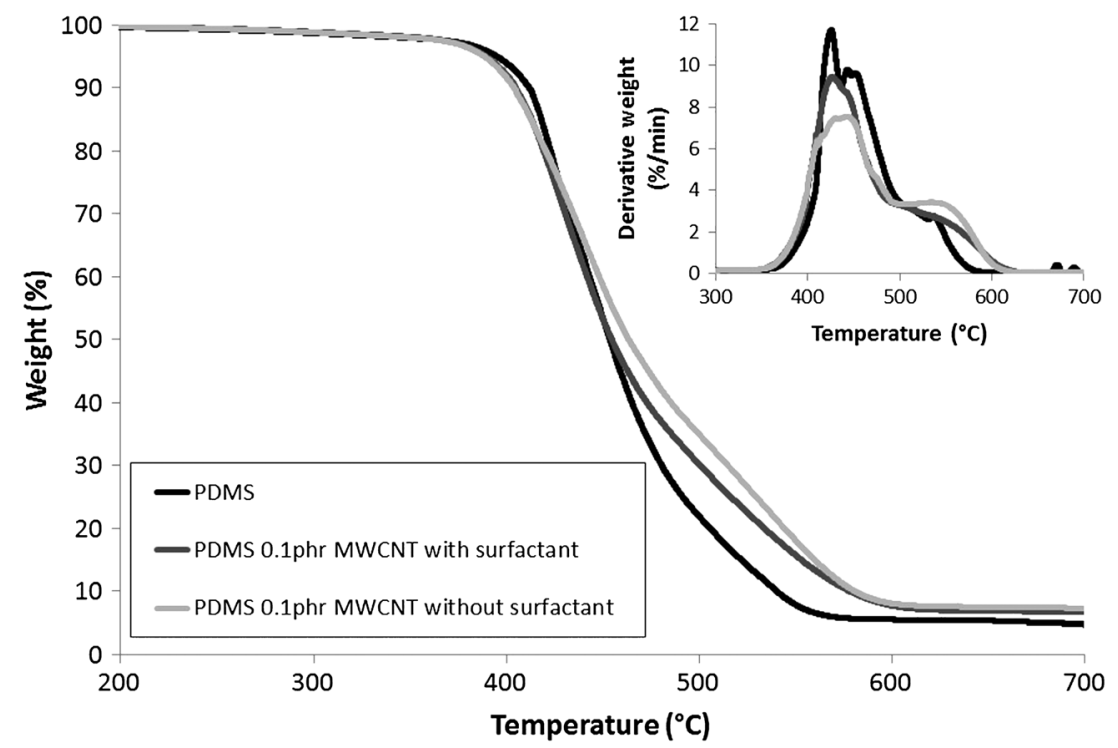

Figure 8. Weight and derivative weight versus temperature for PDMS and PDMS filled with 0.1 phr of MWCNT (with and without surfactant).

test conditions (as heat flux for example). ${ }^{[34]}$ It is generally considered that pyrolysis is anaerobic after ignition when oxygen is consumed in the flame. But before ignition, pyrolysis can be aerobic. Figure 8 shows the thermogravimetric curves for PDMS and PDMS filled with 0.1 phr of MWCNT (with and without surfactant) under air flow. Few differences can be found between three formulations. Temperature at $5 \mathrm{wt} \%$ of mass loss is the same for both composites $\left(388-389^{\circ} \mathrm{C}\right)$ and slightly higher for pure PDMS $\left(395^{\circ} \mathrm{C}\right)$. Same difference is observed for temperature at $10 \mathrm{wt} \%$ of mass loss $\left(404-405^{\circ} \mathrm{C}\right.$ and $412^{\circ} \mathrm{C}$, respectively). Above $425^{\circ} \mathrm{C}$, composites are more stable than unfilled PDMS. Slightly higher residue yields are also observed for composites (7.5 wt\%) than for PDMS (5.3 wt\%) at high temperature $\left(650^{\circ} \mathrm{C}\right)$. We can also notice that the presence of surfactant does not change the beginning of the pyrolysis (up to $425^{\circ} \mathrm{C}$ ) but modifies slightly the degradation pathway above $425^{\circ} \mathrm{C}$ (higher mass loss rate in the range $415-450^{\circ} \mathrm{C}$ corresponding to the peak of mass loss rate, and lower mass loss rate in the range $500-600^{\circ} \mathrm{C}$ ). The residue yield is unchanged. Li et al. have observed that CNTs increase the thermal oxidative stability of silicone rubber. ${ }^{[35]}$ Temperature at $50 \%$ of weight loss increases from 524 to $548^{\circ}$ C. The CNT content investigated in their study ( 3 phr) was much higher than the MWCNT content used in our work. Nevertheless, no improvement in the thermal stability of styrene-butadiene rubber (SBR)/MWCNT composites has been observed even at filler content as high as 10 phr. $^{[36]}$

Considering these results, particularly at low temperature $\left(400^{\circ} \mathrm{C}\right.$, i.e. at the beginning of the degradation process), it can be assumed that variations in time-to-ignition are not controlled by the changes in thermo-oxidative stability of PDMS due to the incorporation of MWCNT.

Figure 9 shows the time-to-ignition versus transmittance for thin specimens $(2 \mathrm{~mm})$. Time-to-ignition decreases when the transmittance decreases, i.e. when the samples become more and more opaque. It is a clear indication that heat flux is only partially absorbed for translucent composites, and therefore the heating rate at the surface is slower. Of course, to evaluate properly the absorption of the heat flux radiated by the

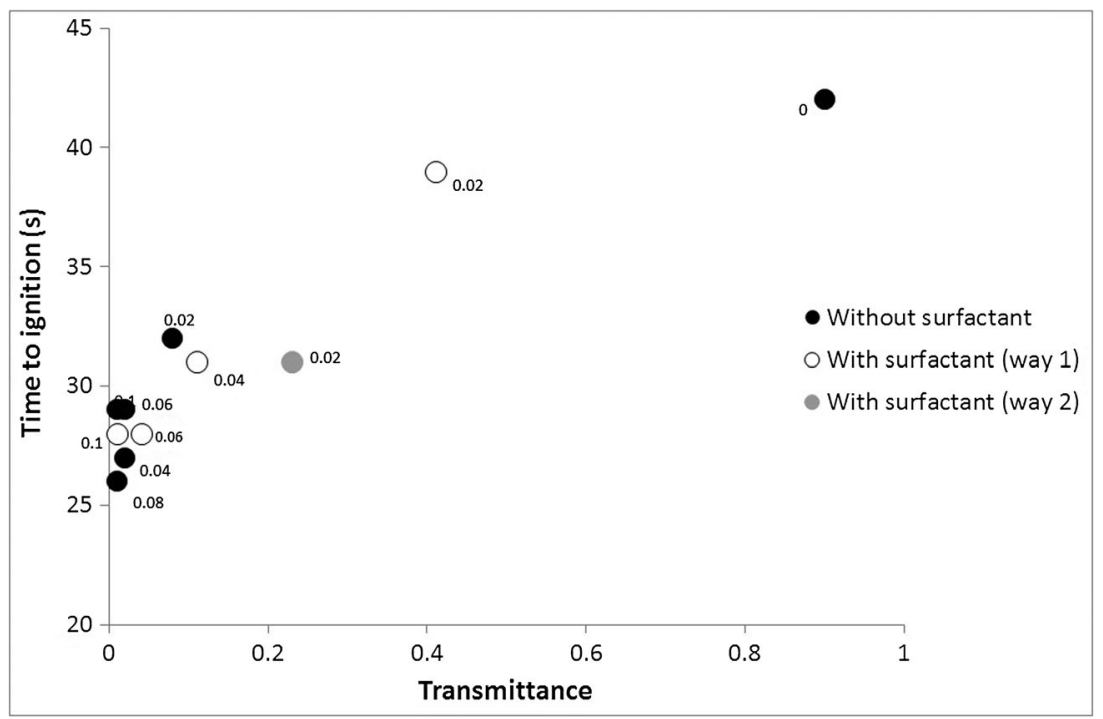

Figure 9. Time-to-ignition versus transmittance for 2-mm-thick composites (labels indicate the MWCNT content of the composites). 


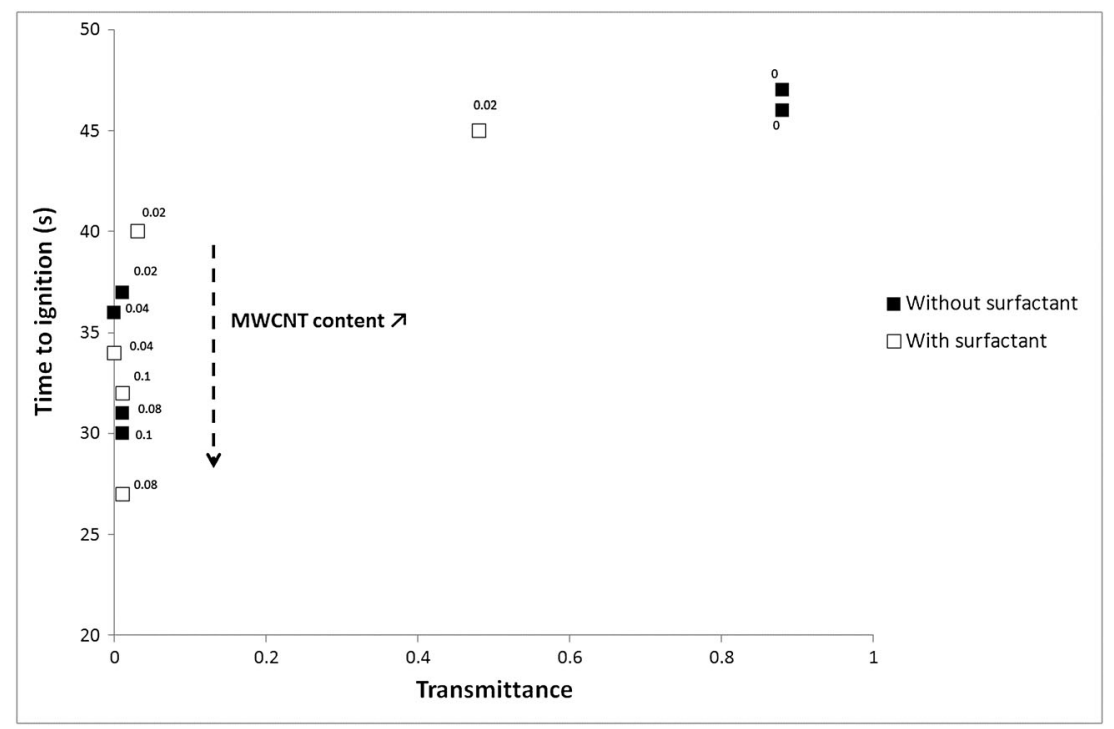

Figure 10. Time-to-ignition versus transmittance for 4-mm-thick composites (labels indicate the MWCNT content of the composites).

epiradiator, we need to know the emission spectrum from the epiradiator and the absorption spectrum of samples over the same wavelength range. Absorption spectrum of PDMS specimens is very difficult to measure quantitatively due to its elastomeric nature (which does not allow cutting a fine layer). Emission spectrum of epiradiator is not known. Kashiwagi et al. said that the heater element of a cone calorimeter covers from the visible to the far infrared with a peak at $2.7 \mu \mathrm{m}$ (i.e. mid infrared).$^{[8]}$ In our work, absorption coefficient is measured at $940 \mathrm{~nm}$, i.e. in near infrared. Despite these approximations, we assume that the measured transmittance values give a good indication of the heat absorption by the specimens.

Figure 10 shows the time-to-ignition versus the transmittance for thicker specimens $(4 \mathrm{~mm})$. Time-to-ignition also decreases when transmittance decreases, but most composites exhibit complete absorption (transmittance is equal to 0 ). For these fully opaque composites, time-to-ignition decreases when MWCNT content increases. Even if heat is fully absorbed for these composites, the heat penetration (i.e. the absorption in-depth) is different, as proved by the transmittance values for the thinner counterparts (Fig. 5). Therefore absorption in-depth can also explain the changes in time-to-ignition for thick composites. When MWCNTs are incorporated into PDMS, heat is absorbed into a thinner layer, and heating rate of the upper surface is faster.

Temperature of the lower surface was also recorded using IR pyrometer. In these experiments, the lower surface was not coated by a graphite layer. Just after exposing to epiradiator, a relatively fast increase is observed for pure PDMS (thickness $2 \mathrm{~mm}$ ) from 29.5 to $37^{\circ} \mathrm{C}$ at $1.5 \mathrm{~s}$ (Fig. 11). A linear but slower heating is observed after $1.5-2 \mathrm{~s}$. Such fast increase can be assigned to an incomplete heat absorption by the specimen. Therefore a fraction of heat is directly received by the IR pyrometer. Similar but much more significant phenomenon can be noticed for pure polyethylene even with a thickness of $4 \mathrm{~mm}$

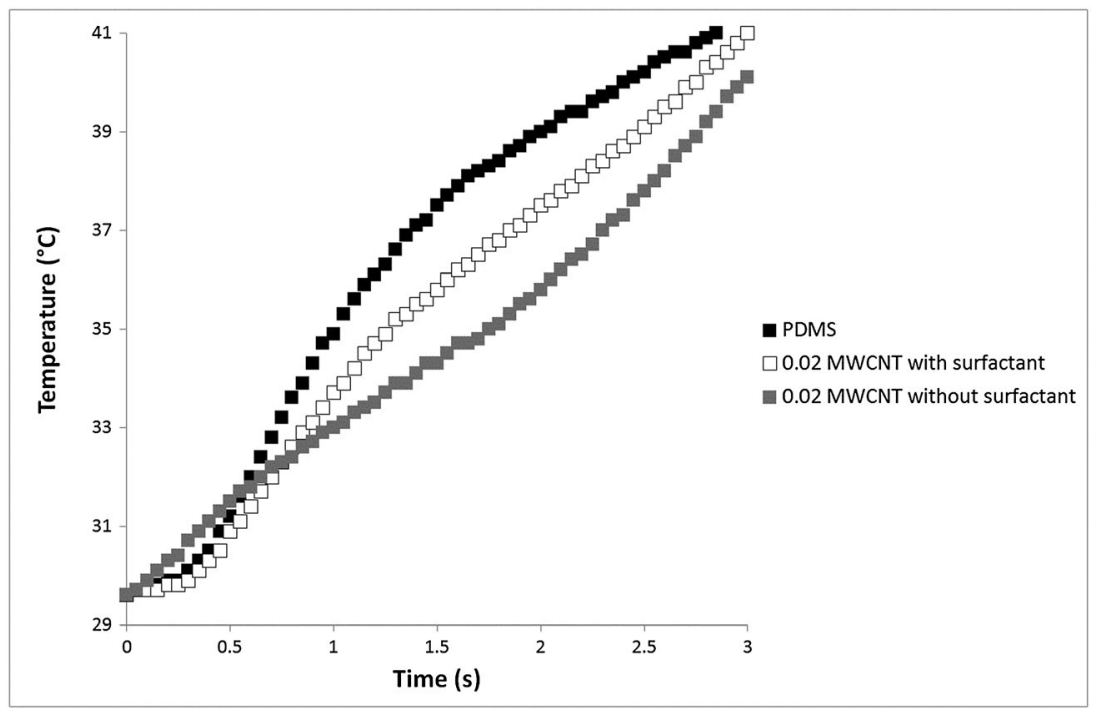

Figure 11. Temperature of the lower surface during epiradiator test for pure PDMS and two composites containing 0.02 phr MWCNT with and without surfactant. 
(data not shown). Translucent composite filled with $0.02 \mathrm{phr}$ of MWCNT (prepared with surfactant according to way 1) also exhibits a faster heating rate in the few first seconds (temperature increases from 29.5 to approximately $35^{\circ} \mathrm{C}$ ). On the contrary, opaque composite filled with 0.02 phr of MWCNT (prepared without surfactant) hardly shows fast heating: heating rate is linear almost from the beginning of the test. In this case, heat absorption is complete, and temperature increase of the lower surface is only due to heat conduction.

Among the properties discussed above, absorption in-depth appears to be the main parameter affecting the heating rate of the upper surface and so on the time-to-ignition. Nevertheless,
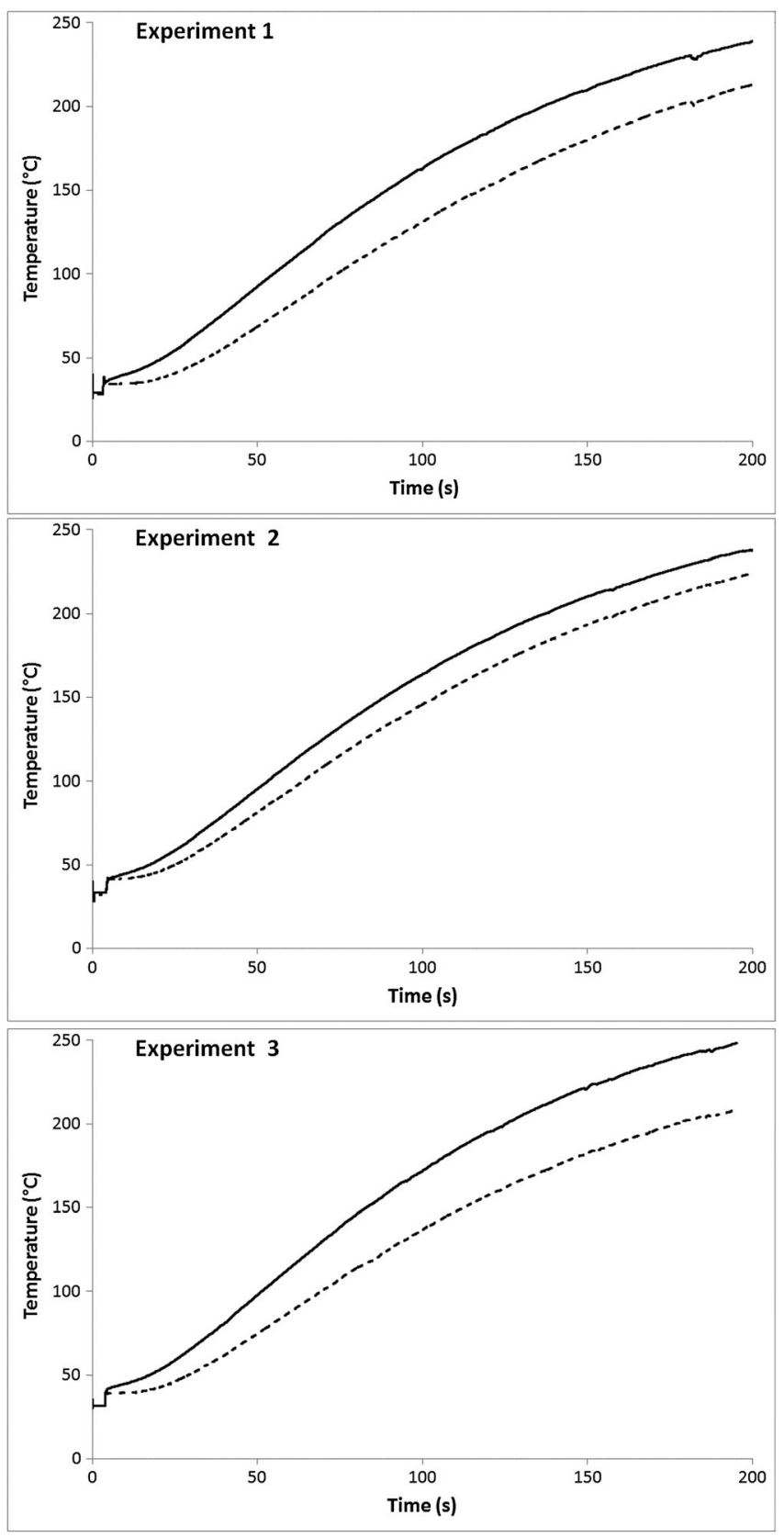

Figure 12. Evolution of temperature of the lower surface for 4-mm-thick PDMS and 4-mm-thick PDMS filled with well-dispersed $0.02 \mathrm{phr}$ of MWCNT using epiradiator equipped with IR camera (solid lines correspond to samples coated on lower surface; dashed lines correspond to samples coated on both surfaces). emissivity is another influent parameter. Emissivity was not directly measured in this work. But, in order to discriminate between the respective influences of both parameters (emissivity and absorption in-depth), additional experiments were carried out.

In these experiments, the specimen coated on both surfaces absorbs the whole heat flux because the emissivity of its upper surface is 1 . The specimen uncoated on upper surface absorbs less heat due to its unknown but non null reflectivity (i.e. emissivity less than 1). Therefore the heating rate of the lower surface should be higher for the specimen coated on both sides. Results are given in Fig. 12. In experiment 1, the sample was 4-mm-thick pure PDMS (with a transmittance measured equal to 0.88 ). The specimen coated on both sides was positioned so that it received a slightly higher external heat flux. But surprisingly the heating is faster for the specimen coated only on lower surface.

In experiment 2, the same procedure was applied with the sample filled with well dispersed 0.02 phr of MWCNT (transmittance equal to 0.48 ). Similar results are obtained. The difference in temperature of the lower surface after $200 \mathrm{~s}$ is $15^{\circ} \mathrm{C}(238$ versus $223^{\circ} \mathrm{C}$ ).

When the positions of both specimen are reverse (i.e. the external heat flux is slightly higher for the specimen coated only on the lower surface-experiment 3 ), the difference is even higher: 248 versus $208^{\circ} \mathrm{C}$ after $200 \mathrm{~s}$.

These results evidence that absorption in-depth has much more influence on ignition than emissivity for our systems. The heating of the lower surface is faster for the specimen only coated on the lower surface because the heat flux is not fully absorbed on the upper surface but penetrates deeper. In return, the heating of the upper surface is limited and ignition (which starts when a critical temperature of the upper surface is reached) occurs later. Of course, a lower net heat flux on upper surface due to a lower emissivity for PDMS slightly filled with MWCNT may be an additional but secondary cause for a delayed ignition.

\section{CONCLUSIONS}

Multiwall carbon nanotube-filled PDMS networks were prepared using the sonication process with and without the use of a surfactant added before and after exfoliation of the nanotubes. It is shown that the processing conditions have a strong effect on the composite properties essentially on the transmittance properties that are very sensitive to the nanotube dispersion in the elastomeric matrix. Only very low filler contents were incorporated into the silicone matrix on account of the strong increase in viscosity obtained by addition of carbon nanotubes.

Time-to-ignition of these composites tends to decrease with increasing contents of MWCNT. Moreover, time-to-ignition is higher for samples exhibiting good dispersion of MWCNT, i.e. those filled with very low contents of MWCNT (0.02 phr) dispersed using surfactant and ultrasonic treatment.

Various characterizations were carried out to explain these observations. Differences in time-to-ignition cannot be assigned to variations in thermal stability, density, specific heat or thermal conductivity. Absorption in-depth rather than emissivity was identified as the predominant parameter leading to higher time-to-ignition for composites exhibiting low IR absorbance. 
Our study confirms that absorption in-depth can be one of the most important parameters. But, even if it is also shown that a good dispersion of MWCNT allows delaying ignition, it must be kept in mind that the influence of the dispersion is only effective for very low contents of MWCNT.

\section{REFERENCES}

[1] B. Schartel, M. Bartholmai, U. Knoll, Polym. Adv. Technol. 2006, 17, 772-777.

[2] M. Bartholmai, B. Schartel, Polym. Adv. Technol. 2004, 15, 355-364.

[3] T. Kashiwagi, J. Fagan, J. F. Douglas, K. Yamamoto, A. N. Heckert, S. D. Leigh, J. Obrzut, F. Du, S. Lin-Gibson, M. Mu, K. I. Winey, R. Haggenmueller, Polymer 2007, 48, 4855-4866.

[4] S. Bourbigot, S. Duquesne, C. Jama, Macromol. Symp. 2006, 233, $180-190$.

[5] F. Samyn, S. Bourbigot, C. Jama, S. Bellayer, Polym. Degrad. Stab. 2008, 93, 2019-2024.

[6] T. Kashiwagi, M. Mu, K. Winey, B. Cipriano, S. Raghavan, S. Pack, M. Rafailovich, Y. Yang, E. Grulke, J. Shields, R. Harris, J. Douglas, Polymer 2008, 49, 4358-4368.

[7] P. Patel, R. Hull, A. Stec, R. Lyon, Polym. Adv. Technol. 2011, 22, 1100-1107.

[8] T. Kashiwagi, E. Grulke, J. Hilding, K. Groth, R. Harris, K. Butler, J. Shields, S. Kharchenko, J. Douglas, Polymer 2004, 45, 4227-4239.

[9] T. Kashiwagi, D. Du, K. I. Winey, K. M. Groth, J. R. Shields, S. P. Bellayer, H. Kim, J. F. Douglas, Polymer 2005, 46, 471-481.

[10] B. H. Cipiriano, T. Kashiwagi, S. R. Raghavan, Y. Yang, E. A. Grulke, K. Yamamoto, J. R. Shields, J. F. Douglas, Polymer 2007, 48, 6086-6096.

[11] B. Schartel, U. Beck, H. Bahr, A. Hertwig, U. Knoll, M. Weise, Fire Mater. 2012, 36, 671-677.

[12] B. Schartel, A. Weiß, Fire Mater. 2010, 34, 217-235.

[13] S. Bellayer, J. W. Gilman, S. S. Rahatekar, S. Bourbigot, X. Flambard, L. M. Hanssen, H. Guo, K. Kumar, Carbon 2007, 45, 2417-2423.

[14] A. Fina, J. Feng, F. Cuttica, Polym. Degrad. Stab. 2013, 98, 1030-1035.
[15] F. Y. Hshieh, C. J. Julien, Fire Mater. 1998, 22, 69-76.

[16] M. Delichatsios, J. Zhang, Fire Mater. 2012, 36, 41-47.

[17] F. Jiang, J. L. deRis, M. Khan, Fire Saf. J. 2009, 44, 106-112.

[18] B. Gardelle, S. Duquesne, P. Vandereecken, S. Bourbigot. Fire Performance of Curable Silicone-based Coatings, ACS book Fire and Polymers VI: New Advances in Flame Retardant Chemistry and Science, (Eds.: C. Wilkie, A. Morgan, G. Nelson), Oxford University Press, 2012.

[19] E. Oztekin, S. Crowley, R. Lyon, S. Stoliarov, P. Patel, R. Hull, Combust. Flame 2012, 159, 1720-1731.

[20] A. Beigbeder, M. Linares, M. Devalckenaere, P. Degée, M. Claes, D. Beljonne, R. Lazzaroni, P. Dubois, Adv. Mater. 2008, 20, 1003-1007.

[21] L. Bokobza, Silicon 2009, 1, 141-145.

[22] L. Bokobza, M. Rahmani, Kautsch. Gummi Kunsts. (KGK) 2009, 62, $112-117$.

[23] H. Takeuchi, C. Cohen, Macromolecules 1999, 32, 6792-6799.

[24] L. Vaisman, H. D. Wagner, G. Marom, Adv. Colloid Interface Sci. 2006, 128-130, 37-46.

[25] C. A. Dyke, J. M. Tour, Nano Lett. 2003, 3, 1215-1218.

[26] L. Bokobza, G. Garnaud, P. Beaunier, J. L. Bruneel, Vib. Spectrosc. 2013, 67, 6-13.

[27] M. Shahzad, M. Giorcelli, N. Shahzad, S. Guastella, M. Castellino, P. Jagdale, A. Tagliaferro, J. Phys.: Conf. Ser. 2013, 439, 1-7.

[28] D. Hopkins, J. Quintiere, Fire Saf. J. 1996, 26, 241-268.

[29] B. Rhodes, J. Quintiere, Fire Saf. J. 1996, 26, 221-240.

[30] B. Schartel, R. Hull, Fire Mater. 2007, 31, 327-354.

[31] Z. Han, A. Fina, Prog. Polym. Sci. 2011, 26, 914-944.

[32] J. Hong, J. Lee, C. K. Hong, S. E. Shim, Curr. Appl. Phys. 2010, 10, 359-363.

[33] L. Bokobza, T. Pflock, A. Lindemann, D. Kwiryn, C. P. Dos Santos, Kautsch. Gummi Kunsts. (KGK) 2014, 67, 45-50.

[34] R. Lyon, J. Quintiere, Combust. Flame 2007, 151, 551-559.

[35] H. Li, S. Tao, Y. Huang, Z. Su, J. Zheng, Compos. Sci. Technol. 2013, 76, 52-60.

[36] L. Bokobza, M. Rahmani, C. Belin, J. L. Bruneel, N. E. El Bounia, J Polym Sci B 2008, 46, 1939-1951. 